\title{
¿Éxito en la Desdicha? A problematização dos conceitos de cultura e interculturalidade nas aulas de ELE a partir de um conto de Leónidas Barletta
}

\section{¿Éxito en la Desdicha? Culture and interculturality concepts' problematization in the SSL classes from a short story by Leónidas Barletta}

\author{
Phelipe de Lima Cerdeira ${ }^{*}$ \\ Universidade Estadual do Oeste do Paraná (UNIOESTE) e \\ Universidade do Estado do Rio de Janeiro (UERJ) \\ Cascavel, Paraná, Brasil
}

\begin{abstract}
Resumo: Escrito nos anos vinte do século XX e publicado a partir da organização da crítica literária Miranda Klix na obra Cuentistas argentinos de hoy (1929), o conto "Desdicha", do escritor argentino Leónidas Barletta, apresenta ao leitor o improvável diálogo entre um zelador de um zoológico e os animais enjaulados, vítimas do seu exotismo, calados pelo seu próprio destino. Ao mesmo tempo em que o narrador conduz a história a partir da insólita conversa entre um trabalhador e um leão ferido, a narrativa permite um desenho do cenário de modernização protagonizado por Buenos Aires, sobretudo para aqueles que não faziam parte da aspiração do ideal de civilização. Por meio da construção de imagens, metáforas e uma descrição sinestésica, a prosa de Barletta permite que o leitor descortine as outras fronteiras da realidade da nação argentina, dando ênfase ao que está às margens, ao que menosprezado e, por fim, à própria ideia de cultura. Dessa maneira, é possível acessar um conceito de cultura que não é estável, mas híbrido (GARCÍA CANCLINI, 2001). Ao resgatar a história de um mais um imigrante e, ao mesmo tempo, compará-la com a solidão de um animal, o conto exemplifica o caráter de mescla (SARLO, 2010) que caracteriza não somente a população da Argentina, mas também de muitos países que receberam europeus nas ondas migratórias do século XIX e XX. Tomando todas essas características, o presente trabalho propõe relatar experiências didáticas de trabalho nas aulas de espanhol como língua estrangeira (ELE), valorizando a dinâmica de leitura do conto literário a partir das experiências e interesses dos próprios alunos (PENNAC, 1996). Para isso, a reflexão estabelece como eixo teórico a problematização do conceito de cultura como uma ferramenta de contato e transformação constante $e$, fundamentalmente, na perspectiva da interculturalidade para entender que nenhuma sociedade pode se compreender por si mesma, reforçando o social através de deslocamentos, fronteiras, choques e interações (GRIMSON, 2011). O conceito de distância estrutural, desenvolvido por Evans-Pritchard nos anos 40 e resgatado por Alejandro Grimson, se transforma também como outra chave de leitura possível para o conto, exemplificando como grupos sociais diferentes, ainda que fisicamente no mesmo espaço, podem não fazer parte do mesmo espaço cultural e simbólico. Temos, assim, uma oportunidade para encarar no infortúnio, na desdicha, uma oportunidade para problematizar os sujeitos pós-modernos.
\end{abstract}

Palavras-chave: Ensino de literatura. ELE. Leónidas Barletta. Interculturalidade.

\begin{abstract}
Written in the first twenty years of the XX century and published from the organization of literary criticism by Miranda Klix in the book "Cuentistas argentinos de hoy" (1929), the short story "Desdicha", which was written by Leónidas Barletta, shows the unlikely dialogue between a zoo's keeper and caged animals, victims of his exoticism, shut up by their own destiny. At the same time the narrator conducts the
\end{abstract}

\footnotetext{
* Doutor em Letras - Estudos Literários pela Universidade Federal do Paraná. Aprovado para o cargo de Professor Adjunto de Língua Espanhola na Universidade do Estado do Rio de Janeiro (UERJ). Realiza estágio de pós-doutoramento em Literatura Comparada na Universidade do Oeste do Paraná sob a supervisão do professor doutor Gilmei Francisco Fleck. E-mail: phelipecerdeira@gmail.com.
} 
story from an unusual dialogue between a worker and an injured lion, the narrative allows a modernization scene's draw in Buenos Aires, mainly for those who were not part of the aspiration of the ideal of civilization. Through the construction of images, metaphors and a synesthetic description, the story of Barletta allows the reader to see the other side of Argentine's reality, emphasizing who is despised and finally the culture idea. In this way, it is possible to access a culture concept, which is not permanent, but hybrid (GARCÍA CANCLINI, 2001). The text redeems the story of one more immigrant, and at the same time it compares with an animal loneliness', explaining the mixture character (SARLO, 2010) which characterizes not only the Argentine's population, but also many other countries that received Europeans immigrants in XIX and XX centuries. Berry in mind all these characteristics, the article proposes to express pedagogical experience in the Spanish as a Second Language, enriching the reading dynamic of the Literature text from students' experience and interest (PENNAC, 1996). For this, the theorical reflection presents the problematization of the culture concept as a contact and transformation tool, in an interculturality to understand that there is no society, which can be understood by itself, increasing the social aspects through the displacements, borders, clash and interactions (GRIMSON, 2011). The structural concept, which was developed by Evans-Pritchard in the 40s and redeemed by Alejandro Grimson, is transformed as another key reading for the text, exemplifying as different social groups, even in the same physical places, cannot be in the same cultural and symbolical space. Therefore, we have an opportunity to face the misfortune, in desdicha, an opportunity to problematize postmodern people.

Keywords: Teaching of Literature. SSL. Leónidas Barletta. Interculturality.

\section{INTRODUÇÃO}

Si yo tuviera tu fuerza para gritar, gritaría, gritaría, gritaría... gritaría hasta que se me reventara el pecho...

(BARLETTA, 1929, p. 22).

É dessa maneira, tal como um eco interminável por reticências, ou como um soco - aquele knockout ao qual se referia Cortázar (2009) ao falar da constituição da natureza de um gênero pouco classificável - que a personagem Ambrosio dá mais um passo para a finalização do conto Desdicha ${ }^{\prime}$, do argentino Leónidas Barletta. Escrito ainda nos anos vinte do século XX, exatamente em 1927 e presente na obra Los Pobres, a narrativa curta foi republicada dois anos depois, em 1929, a partir da organização da crítica literária Miranda Klix, na antologia Cuentistas argentinos de boy. Muestra de narradores jóvenes (1921-1928). Naquela instância, a publicação da obra se justificava como uma iniciativa para apresentar ao campo intelectual daquele momento escritores com projetos narrativos em diferentes dimensões discursivas.

Muito além de cumprir com uma informação anedótica, a alusão ao fato de que o conto atendia ao ideal de apresentar um conjunto disposto a fissurar a estabilidade ou sacralização de um dado campo intelectual literário é representativa para esta discussão inicial por três questões essenciais sob a minha ótica crítica. Dediquemo-nos, pois, a examinar cada uma delas de forma mais detalhada, a fim de que todo o raciocínio tomado para o uso de um determinado conto nas aulas de espanhol como língua estrangeira (ELE) seja melhor percebido e que - assegurada certa pretensão - tal

${ }^{1} \mathrm{O}$ conto não apresenta ainda uma tradução para o português brasileiro. Uma proposta traduzida deste texto já foi criada pelo responsável deste trabalho e será disponibilizada em breve, a partir da publicação de um artigo específico. 
conduta possa se transformar em disparadora para novos diálogos e possibilidades para que a literatura não esteja simplesmente a serviço do exercício da língua enquanto estrutura, mas que personifique um palco no qual é possível ensaiar e viver diferentes conflitos (BAKHTIN, 1986).

A primeira questão anunciada, em um horizonte epistemológico e crítico, ratifica o meu posicionamento de pesquisa ao pensar a literatura a partir da observação de um campo literário diferente (BOURDIEU, 1990), um ponto de vista outro (MIGNOLO, 2003), aquilo que intitulei como Argentum Córdoba². Ao retomar problemáticas estabelecidas a partir de ensaístas como Ezequiel Martínez Estrada, já responsável por tensionar em textos como Radiografía de la pampa (1933) a hipertrofia sistemática realizada nas produções do País do Prata em torno Buenos Aires, ou, décadas depois, de Elsa Drucaroff em Los prisioneros de la torre (2011), foi possível, ao lado dos discentes, elencar elementos para refletir sobre a literatura enquanto resultado discursivo de um dado cânone. As figuras responsáveis por sua manutenção assumem o que o teórico Pierre Bourdieu intitulou como "peso funcional" (BOURDIEU, 2002, p. 31), a determinação de estabelecer - ou melhor, de cristalizar - um projeto que, ora bem, descortina um campo de poder e que atribui aos seus interesses tudo o que pode ser sobrescrito como civilização, repelindo, ao mesmo tempo, tudo o que é diferente com a chancela de barbárie.

O que exatamente isso impacta na experiência de um professor e do seu alunado nas aulas de espanhol como língua estrangeira (ELE) para ler e viver a literatura? Basicamente tudo. No caso especial de tratar a literatura argentina, trata-se, pois, de uma oportunidade para se discutir uma dita argentinidade não sob o ponto de vista do que lhe é comum, mas, sobretudo, do que lhe faz plural, o que lhe permite ser diferente.

O conto de Barletta, em um primeiro nível de leitura, apresenta ao leitor um diálogo improvável entre um cuidador de um zoológico e os animais enjaulados, vítimas do seu exotismo (denominação, infelizmente, comum à conduta e ao trabalho de abordagem de certas variantes linguísticas em detrimento de outras), calados por sua própria sorte. Falar e pensar em cultura e, obviamente, na interculturalidade parece ser inevitável. A partir da voz de um narrador heterodiegético e da marca do discurso direto pontual da já nomeada personagem Ambrosio, Barletta oferece aos seus leitores um conto que exemplifica o trabalho e projeto narrativo da geração de Boedo (vale lembrar que Barletta é um dos representantes do teatro independente e do tensionamento mais direto com nomes da escola de Florida), relacionada à classe operária, voltada à temática de uma cidade responsável por provocar grandes mazelas aos seus cidadãos.

Ainda que não anunciando diretamente aos discentes envolvidos o significado de pensar a literatura argentina a partir do que entendo como tropo literário Argentum Córdoba, passou a se ver candente o exercício do objeto literário como uma proposta de quebra de conhecimento compartimentado ou que fora resultado de uma colonização

${ }^{2}$ Para um maior aprofundamento sobre como foi criado e sistematizado o tropo literário Argentum Córdoba (CERDEIRA, 2019), é recomendável a leitura pontual das duas primeiras seções de minha tese de doutorado. Mais informações podem ser encontras nas Referências. 
do saber. Reiterou-se, por conseguinte, contribuições como as do professor e pesquisador Gilmei Francisco Fleck, que já salientava o quanto "[...] la práctica de lectura y el ejercicio de la escritura rompieron barreras sociales casi insalvables en las jerarquías más rígidas." (FLECK, 2018, p. 184). A simples escolha de um conto de Leónidas Barletta ao invés de uma narrativa de Adolfo Bioy-Casares ou mesmo de Jorge Luis Borges, dessa forma, parte de um posicionamento que entende que as aulas de ELE devem ser tomadas desde o princípio como um espaço de debate e de constante indagação, uma vez que "[...] aprender lenguas extranjeras puede ser un eficiente camino para la descolonización y no una manera o estrategia más de seguir, lenta y progresivamente, imponiendo otras formas de dominación a tantos latinoamericanos." (FLECK, 2017, p. 141).

A segunda questão é, como alguns leitores devem inferir, tangenciada diretamente ao que foi exposto anteriormente. Considerar que as aulas de línguas estrangeiras podem ser tomadas como uma estratégia gradual para fissurar determinadas certezas fortalece o movimento necessário para se questionar uma postura que ora didatiza a literatura como um meio de alguém alcançar uma dada estrutura linguística ou - o que também é questionável - que ora usa o domínio de uma língua para falar superficialmente de literatura. Independentemente de qual seja o movimiento didático do docente, a “[...] elección de una u otra solución determinará la puesta en práctica de modelos que exploten la lengua para llegar a la literatura o modelos en los que sea la literatura la utilizada para llegar a la lengua." (JURADO MORALES; ZAYAS MARTÍNEZ, p. 25).

À vista disso, o que está em xeque é que tanto a língua quanto a literatura são minimizados como enunciados autônomos e dotados de múltiplos de significados. $\mathrm{Na}$ formulação literatura a serviço da língua, há uma conduta que desconsidera o fato de que o texto literário não é apenas um "direito inalienável” (CANDIDO, 2004, p. 191), mas um caminho vivaz para que possamos compreender e (re)significar o(s) mundo(s) que nos $\operatorname{cerca}(\mathrm{m})$, proporcionando "[...] um modo privilegiado de inserção no mundo da escrita, posto que [o letramento literário] conduz ao domínio da palavra a partir dela mesma." (SOUZA; COSSON, 2011, p. 102). Já na concepção que estabelece a língua como coadjuvante da literatura, as cores, contornos e ambiguidades de uma dada língua são silenciados, atendendo ao afã de uma leitura mecanizada, disposta a provar a qualquer custo que se pode ler o literário apenas pelo domínio do código linguístico. Em ambos os casos, não se considera o fato de que a

[...] leitura do mundo precede a leitura da palavra, daí que a posterior leitura desta não possa prescindir da leitura daquele. Linguagem e realidade se prendem dinamicamente. A única compreensão do texto a ser alcançada por sua leitura crítica implica a percepção das relações entre o texto e o contexto. (FREIRE, 2005, p. 11, grifos nossos).

E, por falar na relevância de um dado contexto, quando pensamos na rotina de ensino e aprendizagem que circunscreve as aulas de ELE, há de se ressaltar que são os procedimentos literatura a serviço da língua e língua como coadjuvante da literatura também os 
encarregados de atribuir à dicotomia língua/literatura o objetivo e à cultura um questionável meio. Tal como bem apregoado pela linguista Elena Godoi,

implicitamente se assume que a informação cultural pode "ser servida" como um "prato exótico" e os professores e outros profissionais - ou, pior, muitas vezes, aqueles que se atribuem o direito de ensinar línguas e sobre línguas - preparam aulas, palestras e cursos sobre as festas nacionais, culinária, costumes, etc. Tudo isso obrigatoriamente com o sabor de exotismo folclórico. Nas entrelinhas dos ensinamentos desses profissionais se lê algo como: "olha como 'eles' são esquisitos, olha que porcarias 'eles' conseguem comer, olha se esse é o jeito de se divertir!”. (GODOI, 2010, p. 108-109, grifos nossos).

A terceira e última questão arrolada está ligada à impressão de que a experiência discursiva oferecida por uma língua estrangeira acaba questionando também a própria relação instaurada entre o sujeito leitor e sua língua de origem. Para um emissor lusófono, por exemplo, algumas das questões enunciadas em castelhano não terão a mesma dimensão semântica e pragmática quando pensadas em sua língua materna. Isso porque a "[...] LE provoca, então, efeitos de sentido em um ser que já é efeito da LM. De acordo com Milner (1987), não há como apagar este efeito, senão reduziríamos o falante a aquilo que ele enuncia ou como suporte do calculável." (NUNES, 2010, p. 98).

É muito provável que o peso do léxico desdicha, daquele que não tem sorte ou a graça divina em nenhum aspecto, tenha um impacto diferente daquele alvejado pela alcunha de "desgraçado" em português. Como bem notado por Daniel Cassany, os “[...] significados cambian de lengua a otra, de una cultura a otra, y lo que se construyó para unos no sirve del mismo modo a otros." (CASSANY, 1988, s. n.). As negociações iniciadas pelo simples processo tradutório de uma palavra são, assim, o início de um processo simbólico de trocas e negociações linguísticas, uma porta de entrada não apenas para a já aludida descolonização do saber, mas, fundamentalmente, da quebra de que nas aulas de espanhol como língua estrangeira (ELE) só está em jogo o ensino e o aprendizado de estruturas. Tal como salientado por Lucia Maria Nunes,

[é] necessário superarmos uma concepção puramente instrumental da língua, para podermos escutar aquilo que constitui para os aprendizes o ponto de bloqueio procurando compreender porque não se permitem a aprendizagem. A aprendizagem de línguas estrangeiras esbarra na dificuldade que há para cada um de nós, não somente de aceitar a diferença, mas de fazê-la sua. (NUNES, 2010, p. 101, grifos nossos).

\section{SI YO TUVIERA FUERZA... LA TENEMOS NOSOTROS JUNTOS: OS MODOS DE LER CULTURA E INTERCULTURALIDADE NAS AULAS DE ELE}

Aceitar a diferença e, a partir daí, fazer de tal questão algo familiar e que também nos cerca foi, certamente, o posicionamento tomado para a instituição de distintas experiências de leitura do conto Desdicha em aulas de espanhol como língua estrangeira (ELE). Vale frisar que as instâncias nas quais o conto foi utilizado ocorreram 
no raio discursivo da Universidade Federal do Paraná, a partir da docência no Centro de Línguas e Interculturalidade (CELIN-UFPR) entre os anos de 2014 e 2018 e, ainda, ao ministrar os cursos de extensão Uma literatura que cuenta: lendo diferentes autores argentinos a partir dos contos e Si me cuentas, disfruto, nos anos 2016 e 2017, respectivamente.

Sob a conduta do que Rildo Cosson (2006) intitula como letramento literário, passaram a ser buscados espaços nos quais os discentes demonstrassem não apenas a sua habilidade de compreensão leitora, mas sim, de sujeito-leitor crítico, responsáveis por criar enunciados em diferentes contextos interculturais e capazes de exercer o chamado espírito de agência, isto é, de atestarem um comportamento não passivo diante daquilo que lhes é oferecido.

O aprendizado foi, então, planejado "[...] a partir de una experiencia básica en el uso real de la lengua que garantice una competencia lingüística y comunicativa mínima;" (JURADO MORALES; ZAYAS MARTÍNEZ, 2002, p. 25). Contando com a mediação docente, cada discente se transformava em protagonista, valorizando a proposição de entender "[...] a língua como discurso, concebendo-a como uma prática social de construção de sentidos, sentidos que são atribuídos aos textos pelos sujeitos (em coparticipação com suas comunidades interpretativas)". (JORDÃO, 2016, p. 44).

No conto Desdicha, ao mesmo tempo em que o narrador conduz a narrativa a partir de uma insólita conversa entre um trabalhador e um leão ferido, na verdade, diálogo que pode ser lido como múltiplos solilóquios de Ambrosio, a prosa permite um desenho do cenário de modernização protagonizado por Buenos Aires, sobretudo para aqueles que não faziam parte da aspiração do ideal de civilização. A situação vai muito além de um caso pontual, valorizando a instância do individual como representação também do coletivo: “- Bueno, dije yo, no hay que hacerle; no soy yo el único que pierde a su mujer, y, además, la pobre me ha dejado una hija. Siempre es un gran consuelo.” (BARLETTA, 1930, p. 22, grifos nossos).

A empatia e a aproximação da dor coletiva e a pressuposição da existência de outros casos ajudam a narrativa a transcender os seus limites textuais, propondo leituras contextuais sobre os casos de imigração ultramarina que ocorreram no final do século XIX e começo do século XX na Argentina. Além disso, sendo estrategicamente anacrônico em relação ao tempo da narrativa, aproximando-se ao espaço-tempo da enunciação e da leitura, é possível acessar discussões produtivas, como os casos de crise humanitária vivenciados por refugiados de países como a Síria, o Haiti e algumas nações da América Central, problematizando a questão da interculturalidade, a diversidade e a crise de cultura.

Ao falar de crise de cultura, faço alusão aqui ao que propõe o antropólogo Alejandro Grimson (2011). A crise cultural não está, como se pode supor, relacionada a uma crise económica ou política. A crise cultural, ao contrário, estaria relacionada a uma espécie de mudança ainda mais complexa e, de alguma maneira, simbólica: "Entendemos específicamente la crisis cultural como una suspensión del sentido común y del imaginario acerca de quiénes somos." (GRIMSON, 2011, p. 14). Em termos dos estudos de identidade, de acordo com Grimson, ao falar em crise, é necessário pensar na “autonomía de los actores" para tratar de alguns temas e continuidades. Há, aqui, um 
paradoxo interessante, uma vez que os tempos de multiplicidade cultural são os mesmos dos movimentos fundamentalistas.

Voltando a pensar no objeto literário cotejado, a escolha pelo conto de Barletta pressupõe, como vimos, uma epistemologia para entender o exercício crítico ao falar da literatura argentina - escapando daquilo que costuma ser tratado como representação de nação, sobretudo no contexto acadêmico brasileiro -, mas reforça ainda mais a perspectiva de entender a força subjacente ao fazer literário. Escolher Barletta busca sair da fronteira do canônico para pensar a literatura argentina no Brasil, exatamente para pensar em alguém que se referiu a Jorge Luis Borges, um dos marcos quase intocáveis e inquestionáveis da literatura ocidental e argentina de maneira tão fuzilante: "Cachafaz... Fracasado... El pobre Borges... Vate criollo y vate septuagenario... Buscador de puestitos... Pergeñador de cuentos persas... y lávese de toda esa mugre metafísica." (BARLETTA apud KOREMBLIT, 1987, s/n).

O tecido literário é entendido, por isso, como um discurso vivo, feito por, com e entre as palavras, tendo a língua como prática social (HYMES, 1972), essa arena de conflitos, tal como já havia definido Mikhail Bakhtin (1986). Sem dúvida alguma, antes de tomar o conto de Barletta de maneira direta para problematizar os conceitos de cultura e de interculturalidade, vale a pena pontuar algo anterior e que faz parte desse artigo especificamente: a reflexão sobre o uso da literatura no contexto de ensino e aprendizagem de espanhol como língua estrangeira (ELE).

A conduta ao relacionar o objeto literário à ideia de algo não pragmático e que está afastado da língua somente pontua a incompreensão e o não alinhamento dos profissionais envolvidos nas transformações sofridas na crítica literária e nos estudos linguísticos. Trata-se, pois, de um afastamento do que o francês Daniel Pennac, em seu ensaio seminal Como una novela (1996), considera como parte relevante do processo de ler: a fruição, a sensação de disfrutar o texto literário e de plasmar o quanto o "[...] verbo leer no tolera el imperativo." (PENNAC, 1996, p. 11). Faz parte do enunciado de Pennac a ideia também de não fazer da leitura do professor uma leitura única, a leitura correta. Diante desse posicionamento congelado e monológico, esquece-se de pensar a cultura como um resultado de processos de hibridação, de mudanças constantes a partir do contexto de enunciação e de recepção.

$\mathrm{O}$ argumento de que o castelhano contido em uma narrativa de José Martí é diferente do que se produz em uma conversa entre jovens na Cidade do México ou que os versos de Mario Benedetti desplazan como se fala a língua espanhola, por exemplo, não pode ser tomado como verdade para justificar a não apresentação de um texto literário a um grupo de estudantes. Caso sigamos ao limite com esta máxima, então, o que ocorreria com as sentenças congeladas, tais como "Estoy de acuerdo, Me encantan mis calcetines marrones” ou mesmo com a onipresente "Hola, ¿qué tal?”. Faz-se necessário o questionamento, uma vez que essas estruturas podem apresentar-se pouco pragmáticas no momento de tensão discursiva no Chile ou para expressar a felicidade de uma menina ganhando um presente de Natal, ou, ainda pior, para representar o encontro de um casal em uma noite em Porto Rico. 
Trabalhar com um conto de Leónidas Barletta é, enquanto exercício docente, uma oportunidade de se aproveitar para contrapor diferentes maneiras de escrever, valorizando questões que tangem à sintaxe de uma variante específica ou mesmo que ressignificam uma frase aparentemente simples. Repensando a maneira de se trabalhar o tecido literário em sala de aula, principalmente a partir da década de 80 do século XX, outros teóricos desenvolveram estudos substanciais: H. G. Widdowson (1984), M. Gilroy \& B. Parkinson, Cassany (1994).

No que se refere ao conto, a partir da construção de imagens, metáforas e uma descrição sinestésica, a prosa de Barletta conduz o leitor a outras fronteiras da realidade e, sobretudo, do projeto de nação argentina que se fundamentou a partir da dicotomia sarmientina civilização versus barbárie. Em uma primeira leitura, foi possível dar ênfase ao marginal, ao cidadão menosprezado e, por fim, à própria ideia de cultura:

- Después - sigue Ambrosio - vine aquí y de aquí no me he movido. Hace catorce años que te doy el alimento. Cuando te trajeron me diste mucha lástima. Yo decía: éste también vino de viaje. Dejó las cosas que le gustaban y que conocía y vino a parar a una jaula para asombrarse a la gente. (BARLETTA, 1930, p. 20-21, grifos nossos).

$\mathrm{Na}$ fala da personagem Ambrosio, está presente, em um primeiro nível de leitura, a evidência sobre os animais trasladados de diferentes partes do mundo, que passaram a povoar o primeiro zoológico da América Latina, fundado em 1875. Sem dúvida alguma, oferecendo uma leitura mais atenta ao plano discursivo presente no conto, foi proposta uma leitura sobre a ideia plasmada sobre os outros que vieram para a Argentina, humanos, imigrantes que, para muitos, também lhes parecia exóticos, com a sua fala e acento diferentes, os outros que passaram a fazer parte de uma dimensão nosotros, apartados do que seria o coletivo nosotros. No plano textual, a relativização e a tensão de quem assumiria a dimensão de um nadie, alguém considerado como um ninguém:

- ¡Eh! - dice Ambrosio a media voz - cada uno se queja de su suerte. Toda la gente se queja. Nadie está contento... nadie... nadie... Yo, hace catorce años que estoy aquí y no tengo nada y en Europa, no es por decirlo, tenía de todo... no me faltaba nada... (BARLETTA, 1930, p. 20, grifos nossos).

A partir da leitura do último excerto, é possível decantar de que forma está construída a ideia de resignação dos sujeitos, evidenciando, ainda, a crueldade e aceitação do infortúnio:

- Quédate quieto - refunfuña Ambrosio - no me gusta verte intranquilo. Los que sufren deben ser más buenos todavía... más buenos... aunque a veces... no sé... si tuviera la fuerza que tenés jah! sí... gritaría... gritaría para sacarme la rabia y sería capaz de clavarle las uñas a cualquiera o de clavármelas yo mismo en el pecho (BARLETTA, 1930, p. 21, grifos nossos).

Ao estabelecer uma leitura mais atenta, será possível acessar um conceito de cultura que não é estável, mas híbrido (GARCÍA CANCLINI, 2001). Ao resgatar a 
história de mais um imigrante e, ao mesmo tempo, compará-la com a solidão da um animal, o conto exemplifica o caráter de mescla (SARLO, 2010) que caracteriza não apenas os habitantes argentinos, mas de muitos países que receberam a imigração europeia a partir de ondas imigrantes do século XIX e XX, como o caso da porção sul do Brasil e - permitindo-me, mais uma vez, a uma anacronia histórica - o que ocorre hoje com o tema das migrações internas no Brasil com a presença de haitianos, bolivianos e venezuelanos. Falamos, claro, de sujeitos com culturas diferentes, agentes de diferentes culturas, exemplos para problematizar o que está posto pela personagem Ambrosio construída por Barletta: "La verdad es que la vida es triste. Las amarguras muchas, y las alegrías pocas, y somos todos muy desdichados..." (BARLETTA, 1930, p. 21).

A partir disso, foi possível averiguar o que o alunado sabia a respeito da população argentina, quais eram as impressões relacionadas à população do país austral e as marcas de suas culturas (sempre era oferecida aos alunos a perspectiva de se falar em culturas, isto é, no plural). É impossível pensar em uma ideia de cultura homogênea, sem tensões, capaz de representar o "carácter borroso de las fronteras e híbrido de las culturas" (GRIMSON, 2011, p. 22).

\section{A LEITURA COMO PROCESSO DE (RE)LEITURAS: ALGUNS PROCEDIMENTOS PARA RESSIGNIFICAR O CONTO DESDICHA}

Como dito ao final da seção de introdução, as experiências realizadas com as leituras de Desdicha foram conduzidas na Universidade Federal do Paraná, a partir de aulas de ELE para discentes do Centro de Línguas e Interculturalidade (CELIN) e, ainda, para alunos do Curso de Letras, matriculados em cursos de extensão voltados à literatura. Para cada grupo, foi tomada como ponto de partida a ideia inicial de fruição literária. E como despertar o prazer pela literatura? Lendo. Ou, como diria o francês Daniel Pennac (1996), não pedindo, a princípio, nada em troca:

Una sola condición para esta reconciliación con la lectura: no pedir nada en cambio. Absolutamente nada. No construir ninguna muralla de conocimientos preliminares alrededor del libro. No plantear la más mínima pregunta. No poner ni la más pequeña tarea. No añadir ni una sola palabra a las de las páginas leídas. Ningún juicio de valor, ninguna explicación del vocabulario, nada de análisis de texto ni de indicaciones bibliográficas... Prohibirse del todo "hablar sobre".

Lectura-regalo. (PENNAC, 1996, p. 123).

Criar um estado no qual o ler é adjetivado e passa, assim, a transcender uma ação mecanizada para se constituir em um espaço-tempo intitulado leitura-presente foi o primeiro estágio oferecido para ressignificar o conto Desdicha. Em um primeiro momento, a decisão pela leitura individual e silenciosa buscava justamente que cada participante pudesse criar sentidos em torno do texto literário, levantando hipóteses e diálogos para uma segunda fase de interação. Outrossim, esperava-se que os leitores pudessem fomentar questionamentos a respeito da ideia de cultura e, sobretudo, da identidade das personagens do conto, buscando semelhanças, diferenças, enfim, vasos 
comunicantes com os seus distintos espaços discursivos. Nesse aspecto, o pesquisador Rildo Cosson sacramenta que na

[...] leitura e na escritura do texto literário encontramos o senso de nós mesmos e da comunidade a que nos pertencemos. A literatura nos diz o que somos e nos incentiva a desejar e a expressar o mundo por nós mesmos. E isso se dá porque a literatura é uma experiência a ser realizada. É mais que um conhecimento a ser reelaborado, ela é a incorporação do outro em mim sem renúncia da minha própria identidade. No exercício da literatura, podemos ser outros, podemos viver com os outros, podemos romper os limites do tempo e do espaço de nossa experiência e, ainda assim, sermos nós mesmos. (COSSON, 2006, p. 17, grifos nossos).

Passado o estágio de experiência leitora, foi oferecido um momento no qual todos os envolvidos, a partir da mediação do professor, pudessem compor uma espécie de nuvem semântica no quadro com palavras, conceitos e demais idiossincrasias literárias do conto de Barletta. As últimas - retrato óbvio da experiência de uma leitura mais profissional e crítica - foram mais constantes nas duas dinâmicas relacionadas aos cursos de extensão, retratando um interesse claro de graduandos do Curso de Letras.

Em segundo momento, para potencializar a possibilidade de ler o texto literário para além da estrutura da escrita, foi criada uma apresentação pontual para mediar a leitura. A inspiração se deu justamente no enredo que serve como pano-de-fundo da narrativa curta, a partir do retrato de animais enjaulados e que poderiam retratar o cenário de ansiedade e de solidão contrastados pela violência de uma tempestade que acometeu todos os animais presentes no zoológico de Desdicha:

En esto se levanta una tormenta de viento y tierra. Las ventanas del pabellón se cierran con estrépito. Unos vidrios se hacen añicos. Oscurece. Ambrosio corre a cerrar las ventanas. Un vivísimo relámpago ciega las pupilas de las fieras. Duquesa da un salto; la piel del cuello se le eriza. El trueno, un trueno largo, grave, contenido como un rezongo, no tarda en hacerse oír y la lluvia empieza a caer, abundante, fácil, y se experimenta cierto alivio, un como bienestar físico, ahora que el agua cae sin medida. (BARLETTTA, 1930, p. 20).

Assim, antes de iniciar uma segunda rodada de leitura do texto literário, foram apresentados slides que pudessem oferecer a construção de novos sentidos, com imagens relacionadas diretamente ao texto, mas com ampla possibilidade semântica. Logo no início da sequência, ao lado do primeiro texto não-verbal, a imagem de um leão encarcerado (eco e alusão à personagem Nerón, presente no conto Desdicha, de Leónidas Barletta), havia a seguinte inscrição: "Si yo tuviera tu fuerza para gritar, gritaría, gritaría, gritaría... gritaría hasta que se me reventara el pecho..." (BARLETTA, 1930, p. 22). A decisão por não apresentar o período como um fragmento claro do conto, ou seja, sem a menção do nome de Barletta ou da página da qual provinha o excerto buscou construir os sentidos propostos pelo texto original, estimulando que os envolvidos pudessem expandir sentimentos provocados anteriormente pelo texto literário para contextos extraliterários.

O uso de slides com retratos de animais (macacos, ursos, elefantes etc.) não mencionados na prosa de Barletta permitiu, ainda, que os participantes negociassem 
certas hipóteses e subsidiassem os seus raciocínios a partir de um repertório leitor mais variado, crítico e contemporâneo. O jogo com o conhecimento de mundo de cada leitor e, ao mesmo tempo, com o horizonte de expectativas do grupo permitiu que a própria escolha de um conto da década de vinte do século passado fosse melhor dimensionada. Tal como apregoado pelos estudiosos José Jurado Morales e Francisco Zayas Martínez,

[e]l análisis de las épocas presenta la especial consideración del factor de lejanía temporal. Esta lejanía temporal puede ir referida al mundo literario o al mundo real: el factor de lejanía temporal en el mundo literario no perjudica la aplicación de la obra a la clase de español. [...] No sólo no obstaculizan el desarrollo de la clase, sino que favorecen la imaginación, e incluso potencian la liberación de los límites impuestos por el conocimiento del entorno real. (JURADO MORALES; ZAYAS MARTÍNEZ, 2002, p. 27).

Depois de apresentar os slides com as imagens dos animais e os fragmentos provenientes do conto de Leónidas Barletta, o alunado foi convidado, mais uma vez, a ajudar a compor no quadro uma nuvem semântica com as sensações despertadas pelas imagens e as frases. Após construir esse quadro verbal, foi-lhes ofertado um tempo para reconstruir as primeiras impressões a partir de uma composição de 140 caracteres sobre o que lhes parecia o tema geral, finalizando o que se poderia intitular como fase de préleitura (antes, claro, da segunda leitura do conto).

A partir das contribuições dos leitores, foram destacadas questões ligadas ao papel e ao impacto dos zoológicos em grandes centros urbanos e, ainda, sobre a potência geradora pelas imagens enquanto textos não-verbais. Prevendo que tais eixos fossem cotejados, o professor ofereceu dois textos como disparadores de novas rodadas de discussão e de prática de expressão oral e compreensão leitora. Tratava-se, pois, de uma reportagem publicada no ano de 2016 no portal argentino Infobae. Intitulada como Del activismo a la liberación: cómo fue el caminho para el cierre del Zoológico, a notícia realizava um rápido panorama a respeito do zoológico mais antigo da América Latina, do seu projeto arquitetônico parisiense e modelador de uma sociedade burguesa disposta a querer estabelecer um ideal de civilização europeizante até as recentes discussões protagonizadas por ativistas e organizações não-governamentais responsáveis por demonstrar a viabilidade de transformar os antigos espaços de simples cativeiros em centros ecológicos de proteção e conscientização ${ }^{3}$. De forma análoga, foi explicado aos alunos que as imagens utilizadas na apresentação eram de autoria do fotógrafo argentino Roberto García, e que faziam, por sua vez, parte da obra Tras las rejas. Historias de vida y cautiverio, publicada no ano de 2007.

Em último estágio e incentivando mais uma vez a etapa de leitura, foi oferecido aos alunos um tempo para que pudessem reler o conto, considerando que a nova experiência com o texto literário pudesse oferecer novas possibilidades de construção de sentidos. No último encontro, depois de que todos os alunos estabeleceram a fase de compreensão leitora, postulou-se um estágio no qual o grupo pôde discutir sobre o conto.

\footnotetext{
${ }^{3}$ A notícia publicada pelo Infobae e utilizada nas aulas de ELE figura em nossa seção de Referências.
} 


\section{CONSIDERAÇÕES FINAIS OU SOBRE COMO SOMOS TODOS MUY DESDICHADOS}

Ao mediar a aproximação entre o que está no plano ficcional e a realidade contemporânea da Argentina, do Brasil e de outros países ocidentais (seja por conta dos movimentos migratórios presenciados na América Latina, seja nos deslocamentos humanitários de refugiados instituídos nos Estados Unidos ou na Europa), a narrativa curta ganhou novas possibilidades e significados. Logo, eleger o texto de Leónidas Barletta, um conto literário capaz de oferecer tais possibilidades discursivas é

[d]arle la debida importancia a la enseñanza/aprendizaje de lectura y escritura en la formación de educadores en todos los niveles de la formación docente es una de las vías más eficaces para el desarrollo de una ciudadanía crítica y consciente y de un profesional muy bien preparado para la tarea de enseñar. (FLECK, 2018, p. 182).

Tal como observado desde o início, toda a reflexão proposta a partir da leitura do conto Desdicha buscou como eixo questionador o conceito de cultura, tensionando-o como uma ferramenta de contato e mudança constante e, fundamentalmente, na perspectiva da interculturalidade para entender que nenhuma sociedade pode ser compreendida por si mesma. Sublinhou-se, portanto, o âmbito social a partir de descentralizações, fronteiras, choques e interações (GRIMSON, 2010). O conceito de distância estrutural, desenvolvido por Evans-Pritchard nos anos 40 e resgatado por Alejado Grimson, erigiu-se também como outra chave de leitura possível para o conto, exemplificando como grupos sociais distintos, ainda que fisicamente ocupando o mesmo espaço, podem não fazer parte do mesmo espaço cultural e simbólico. No conto, bastou demonstrar como, em meio ao rebuliço provocado pela tempestade, mesmo em uma condição de desemparo, duas moças da sociedade portenha, com as suas "faldas mojadas" (BARLETTA, 1930, p. 21), acabaram protagonizando a ação mais violenta de todo o conto. Duas jovens que, sondadas pelo foco narrativo, demonstravam a partir do silêncio a falta de empatia ao tornarem invisíveis o zelador Ambrosio e os animais do pavilhão dos felinos. A menção à passagem da narrativa ficcional, obviamente, foi ecoada pelos alunos como proposição para refletir sobre os conceitos de cultura e interculturalidade também a partir de suas vivências discursivas.

$\mathrm{Na}$ ficção do representante do grupo de Boedo, o choque causado pela impossibilidade de pertencimento se ressignificou a partir da mudança das posições entre a dimensão humana e a dimensão animal, animalizando o primeiro e, ironicamente, humanizando o último. Mais uma possibilidade para (re)considerar a lógica do que é a civilização e o que é a barbárie: "El viejo león lo mira tristemente, se mira su pata embadurnada de alquitrán, bate su cola contra los flancos y brama largamente, con un bramido humano.” (BARLETTA, 1930, p. 22, grifos nossos).

Sob a perspectiva de letramento literário, tratou-se de mais um ensejo para ver que, no infortúnio, ou melhor, na desdicha, é viável encontrar não exatamente a redenção, mas uma condição verossímil, uma oportunidade para se problematizar os sujeitos pósmodernos (HALL, 2011). Tal como dito pela personagem de Barletta, no final das 
contas, ficou mais claro o fato de que todos nós "[...] somos muy, muy desdichados." (BARLET'TA, 1930, p. 21).

\section{REFERÊNCIAS}

BAKHTIN, M. Problemas literários y estéticos. La Habana: Editorial Arte y Literatura, 1986.

BARLETTA, L. Desdicha. In: KLIX, Miranda. KLIX, Miranda (Org.). Cuentistas Argentinos de Hoy. Muestra de narradores jóvenes (1921 - 1928). Buenos Aires: Editorial Claridad, 1929.

BOURDIEU, P. El campo literario. Prerrequisitos críticos y principios de método, Critérios, La Habana, n. 25-28, enero 1989-diciembre 1990, p. 20-42. Trad. Desiderio Navarro. Disponível em: <http://educacion.deacmusac.es/practicaslegitimadoras/files/2010/05/bourdieucamp o.pdf. $>$. Acesso em: 17 ago. 2019.

BOURDIEU, P. Campo de poder, campo intelectual. Buenos Aires: Editorial Montressor, 2002.

CANDIDO, A. Vários escritos. São Paulo: Duas cidades, 2004.

CASSANY, D. Describir el escribir. Cómo se aprende a escribir. Barcelona: Paidós, 1988.

CERDEIRA, P. de L. Argentum Córdoba: diálogos, fissuras e soslaios entre ficção e história sob as miradas de Cristina Bajo, Andrés Rivera e María Teresa Andruetto. Tese de Doutorado, Programa de Pós-graduação em Letras, Universidade Federal do Paraná, Curitiba. 569 p.

COSSON, R. Letramento literário: teoria e prática. São Paulo: Contexto, 2006.

CORTÁZAR, J. Algunos aspectos del cuento. Biblioteca virtual Miguel de Cervantes, Alicante, 2009. Disponível em: <http://www.cervantesvirtual.com/obra/algunosaspectos-delcuento/>. Acesso em 10 ago. 2019.

DRUCAROFF, E. Prisioneros de la torre. Buenos Aires: Emecé, 2011.

FLECK, G. F. Enseñanza/aprendizaje de lenguas extranjeras y de literatura: caminos para la descolonización de América. Revista Trama, v. 13, n. 29, 2017, p. 136-156.

FLECK, G. F. Reflexiones por una enseñanza de lengua extranjera que valore la lectura y la escritura como caminos para la descolonización de América Latina. In: LÓPEZ, C. J. et al. (Orgs.). El universo literario en la enseñanza de español como lengua extranjera en Brasil. Porto Alegre: Unioeste, Evangraf/Exclamação, 2018.

FREIRE, P. A importância do ato de ler: em três artigos que se completam. São Paulo: Cortez, 2005. 
GARCÍA CANCLINI, N. Culturas hibridas. Estrategias para entrar y salir de la modernidad. Buenos Aires: Editora Paidós, 2001.

GODOI, E. As guerras pela língua espanhola. In: SALEH, P. B. de O.; OLIVEIRA, S. Linguagem, texto e ensino: discussões do CELLIP. Ponta Grossa: Editora UEPG, 2010.

GRIMSON, A. Los límites de la cultura: crítica de las teorías de la identidad. Buenos Aires: Siglo Veintiuno Editores, 2011.

HALL, S. A identidade cultural na pós-modernidade. Trad. Tomaz Tadeu da Silva. Rio de Janeiro: Editora DP\&A, 2011.

HYMES, D. On Communicative Competence. In: Pride; Holmes (Orgs.). Sociolinguistics. Selected Readings. Harmondsworth: Penguim, 1972.

INFOBAE. Del activismo a la liberación: cómo fue camino para el cierre del Zoológico. Disponível em: <http://www.infobae.com/sociedad/2016/06/26/del-activismo-a-laliberacion-como-fue-el-camino-para-el-cierre-del-zoologico/>. Acesso em 20 set. 2019.

JORDÃO, C. M. No tabuleiro da Professora Tem... Letramento Crítico? In: JESUS, D. M. de; CARBONIERI, D. (Org.). Práticas de Multiletramentos e Letramento Crítico: outros sentidos para a sala de aula de linguas. 1 ed. Campinas: Pontes Editores, 2016, v. 1, p. 41-56.

JURADO MORALES, J.; ZAYAS MARTÍNEZ, F. La literatura en la enseñanza del español como lengua extranjera. Propuesta metodológica y aplicaciones didácticas de textos de la literatura española contemporánea. Cádiz: Universidad de Cádiz, 2002.

KLIX, M. (Org.). Cuentistas Argentinos de Hoy. Muestra de narradores jóvenes (1921 1928). Buenos Aires: Editorial Claridad, 1929.

MARTÍNEZ ESTRADA, E. Radiografía de la pampa. Buenos Aires: Losada, 2011.

MIGNOLO, W. Historias locales, diseños globales. Colonialidad, conocimientos subalternos y pensamiento fronterizo. Buenos Aires: Akal Ediciones, 2003.

NUNES, L. M. Aprender uma língua estrangeira é sempre um pouco tornar-se um outro. In: SALEH, P. B. de O.; OLIVEIRA, S. Linguagem, texto e ensino: discussões do CELLIP. Ponta Grossa: Editora UEPG, 2010.

PENNAC, D. Como una novela. Buenos Aires: Norma, 1996.

SARLO, B. Modernidade periférica: Buenos Aires 1920 e 1930. Trad. e posfácio de Júlio Pimentel Pinto. São Paulo: Cosac Naify, 2010.

SOUZA, R. J. de; COSSON, R. Letramento literário: uma proposta para a sala de aula. Univesp, $2011 . \quad$ Disponível em: <https://acervodigital.unesp.br/bitstream/123456789/40143/1/01d16t08.pdf>. Acesso em 15 set. 2019. 